\title{
Saúde e População LGBT: Demandas e Especificidades em Questão
}

Health And LGBT Community: Needs And Specificities Under Discusslon

Salud Y Población LGBT: Demandas Y Especificidades En Cuestión
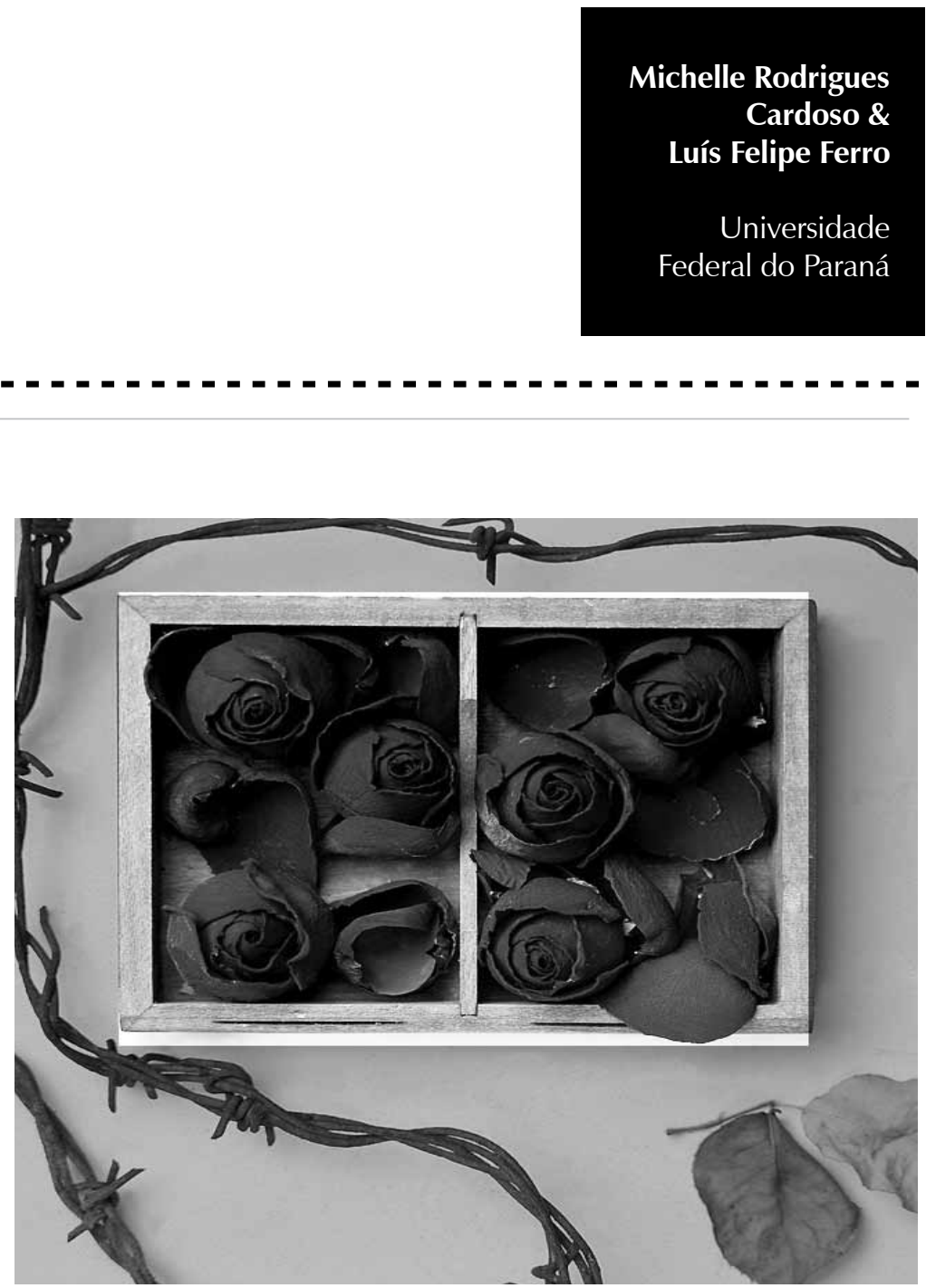
Resumo: A população LGBT - lésbicas, gays, bissexuais e transgêneros - é vulnerável quanto ao atendimento de seus direitos humanos, incluindo o acesso aos serviços públicos de saúde. A partir da eminente necessidade de formação dos agentes da saúde no tema LGBT, assim como da elaboração de ações voltadas para as demandas específicas dessa população, é nossa intenção contribuir para a reflexão sobre alguns dos fatores que podem interferir de maneira substancial no processo de saúde da população LGBT. Aprofundamo-nos sobre algumas das questões próprias a cada segmento, sublinhando a importância da atenção dos profissionais da saúde frente às reações em cadeia que implicam o processo de vulnerabilidade e que conduzem ao adoecimento dessa população.

Palavras-chave: Identidade sexual. Homossexualidade. Lesbianismo. Vulnerabilidade.

Abstract: The LGBT community - lesbians, gays, bisexuals and transgenders - is vulnerable to achieve the fulfillment of their human rights including the access to public health. Assuming the imminent need for the formation of health workers in LGBT theme, as well as for the development of actions to respond to the specific demands of this population, it is our intention to contribute to the reflection on some of the factors that may interfere substantially in the LGBT process of health. We discuss some of the specific issues to each segment, highlighting the importance of attention of health professionals about the chain reactions that involve the process of vulnerability and that lead to illness in this population.

Keywords: Gender identity. Homosexuality. Lesbianism. Vulnerability.

Resumen: La población LGBT - lésbicas, gays, bisexuales y transexuales - es vulnerable en relación al atendimiento de sus derechos humanos, incluyendo el acceso a los servicios públicos de salud. A partir de la eminente necesidad de formación de los agentes de la salud en el tema LGBT, así como de la elaboración de acciones destinadas para las demandas específicas de esa población, es nuestra intención contribuir para la reflexión sobre algunos de los factores que pueden interferir de manera substancial en el proceso de salud de la población LGBT. Profundizamos sobre algunas de las cuestiones propias a cada segmento, subrayando la importancia de la atención de los profesionales de la salud frente a las reacciones en cadena que implican el proceso de vulnerabilidad y que conducen a que esa población enferme.

Palabras clave: Identidad sexual. Homosexualidad. Lesbianismo. Vulnerabilidad.

1 A sigla LGBT atualmente é utilizada pelos ativistas com a finalidade de promover a visibilidade lésbica, sendo que essa sigla pode sofrer alterações de acordo com o contexto

político e regional. Respeitando as

pautas de luta do movimento dos ativistas, neste trabalho, será

adotada a sigla LGBT

(Facchini \& França, 2009, p.63).
A política nacional de atenção especial a lésbicas, gays, bissexuais, travestis e transexuais - $\mathrm{LGBT}^{1}$ teve sua origem junto ao Ministério da Saúde em parceria com os movimentos sociais visando ao combate à AIDS. As ações incluíam a disponibilização de assessoria jurídica, atuação no fortalecimento dos serviços, campanhas de comunicação e ações para a visibilidade dessa população (Brasil, 2008a).

Atualmente, essa parceria apresenta mais de duas décadas de acúmulo teórico e de ações de promoção à saúde, o que conduziu à ampliação das políticas públicas para além do combate à AIDS. Para Lionço (2008a), torna-se evidente a preocupação do poder público com as questões da saúde LGBT quando o desafio da construção de uma política de atenção integral à saúde é elaborada através do programa do governo federal Brasil sem Homofobia. O programa, criado em 2004, estabelece diretrizes para o combate à violência e à discriminação, além da promoção da cidadania homossexual (Brasil, 2004).

A população LGBT, devido à não adequação de gênero com o sexo biológico ou à identidade sexual não heteronormativa, tem seus direitos humanos básicos agredidos, e muitas vezes se encontra em situação de vulnerabilidade. Diante dessa realidade, o Ministério da Saúde reconhece que a identidade sexual e a identidade de gênero são constituintes de um processo complexo de discriminação e de exclusão, do qual derivam os fatores de vulnerabilidade, tais como "a violação do direito à saúde, à dignidade, à não discriminação, à autonomia e ao livre desenvolvimento" (Brasil, 2008b, p. 571).

Segundo dados apresentados pelo Ministério da Saúde, dois em cada três entrevistados (67\%) já sofreram algum tipo de discriminação motivada pela identidade sexual ou pelo 
"Eles/elas têm duas opções: ou correr aos poucos médicos homossexuais assumidos que cobram caro para atendê-los, ou usar clínicas públicas onde são vítimas do desrespeito e mau tratamento"

(Okita, 2007, p. gênero, proporção que alcançou $85 \%$ em travestis e transexuais. Os dados desse documento também apontam que 14,5\% dos participantes do estudo feito na Parada Gay de São Paulo relataram já terem sofrido algum tipo de preconceito nos serviços da rede de saúde (Brasil, 2008b).

Atualmente, observamos um salto de qualidade no que se refere aos serviços públicos de saúde que visam a atender as demandas dessa população. Apesar dos dados preocupantes apontados pelos indicadores do SUS, podemos observar as mudanças significativas através do relato proferido na década de 1980: "Eles/elas têm duas opções: ou correr aos poucos médicos homossexuais assumidos que cobram caro para atendê-los, ou usar clínicas públicas onde são vítimas do desrespeito e mau tratamento" (Okita, 2007, p. 84).

Os avanços evidenciados revelam boas perspectivas, porém Sousa, Abrão, Costa e Ferreira (2009), citando Lionço, afirmam que o processo de construção de serviços não discriminatórios na área da saúde enfrenta diversas barreiras diante de uma sociedade na qual a heterossexualidade se configura como um padrão amplamente difundido.

As transformações das redes de saúde para o melhor atendimento dessa população também dependem das transformações no modo de pensar e de agir dos profissionais de saúde. As questões culturais advindas do padrão heterossexual influenciam de modo subjetivo o atendimento dos profissionais da saúde a essa população. Sousa, Abrão, Costa e Ferreira (2009), a partir dos argumentos de Lionço, relacionam a prática discriminatória de alguns profissionais da saúde com a influência do padrão heterossexual que permeia a nossa cultura, sendo que o preconceito sofrido pela população LGBT pode constituir uma barreira que impede o seu acesso aos serviços de saúde.
Miller (2002) destaca que uma postura reflexiva frente aos padrões heterossexuais socialmente estabelecidos ajuda a prevenir a discriminação, afirmando incisivamente a necessidade iminente da formação profissional dos agentes em saúde para ações frente às especificidades da população LGBT.

A partir desse cenário, é nossa intenção compor material reflexivo que permita aos profissionais da saúde identificar fatores que podem interferir de maneira substancial no processo de saúde da população LGBT, de maneira a fornecer subsídios para discussões e elaborações de práticas em saúde mais focadas nas necessidades dessa população.

Como guia para a apresentação dos dados ao leitor, propomos inicialmente uma introdução quanto à homofobia, sublinhando a importância do conceito em sua relação com a saúde da população LGBT. A seguir, aprofundaremos a discussão no tocante ao campo da saúde, ressaltando as diferentes demandas e vulnerabilidades às quais está exposta a população LGBT.

Nossa intenção primeira é contribuir para que os profissionais da saúde visualizem e reflitam sobre alguns fatores que podem influenciar de maneira negativa a saúde da população LGBT e conduzir diversos indivíduos a um processo de adoecimento.

\section{Homofobia: a violência contra a população LGBT}

De acordo com Ramos e Carrara (2006), desde a década de 80, o movimento homossexual brasileiro tem dado visibilidade aos crimes motivados pela orientação sexual, divulgando o termo homofobia para designar tais atos. Leony (2006, p.1) caracteriza a homofobia como o "ódio explícito, persistente e generalizado; manifesta-se numa escala de violência desde as agressões verbais subsumidas nos tipos penais contra 
a honra até os extremados episódios de violência física, consumados com requintes de crueldade".

Um dos conceitos apresentados por Nascimento (2010) para designar o termo homofobia consiste na classificação infundada dos indivíduos que fogem aos padrões heterossexuais em inferiores ou anormais, rótulo que também pode ser atribuído a algumas diversidades étnicas, raciais e religiosas.

A etiologia dos delitos contra a população LGBT é explicada por Leony como conseqüência da ideologia heterossexista, que situa os homossexuais como "minorias desprezíveis e desprezadas", e, por supostamente viverem na clandestinidade com medo de serem descobertos, são vistos pelos semeadores da homofobia "como alvo fácil de chantagens, extorsões e latrocínios" (2006, p. 5).

Segundo os indicadores do SUS, no período de 1980 a 2005, foram assassinados 2.511 homossexuais no Brasil, sendo que a maior homofóbicos (Brasil, 2008b). De acordo com os relatos obtidos nessa pesquisa, a maioria das violências ocorreu com o envolvimento de pessoas desconhecidas, totalizando $48 \%$ dos casos. Os agressores relacionados com o cotidiano das vítimas estão concentrados nos familiares (12\%), em segundo lugar, citam colegas de escola-faculdade, sendo a terceira maior pontuação referente a amigosconhecidos (9\%); os demais agressores totalizaram 12\% (Brasil, 2008b).

noite, Cinderela

é utilizada para identificar as situações em que são oferecidas bebidas ou alimentos que contêm substâncias entorpecentes à vítima,

facilitando, dessa forma, o roubo ou o estupro (Brasil, 2008b).

Os indicadores do SUS também revelam que as principais formas de violência são agressões verbais ou ameaças de agressões (55\%), seguidas pelas agressões físicas (15\%), chantagem ou extorsões $(11 \%)$, violência sexual $(6 \%)$ e o golpe conhecido pela expressão boa-noite, Cinderela² (3\%) (Brasil, 2008b). parte dos crimes ocorreu por motivos

Paiva (2006) sustenta que os indicadores de saúde refletem a defasagem na promoção, na proteção ou na violação dos direitos humanos. As informações dos indicadores do SUS, publicados em 2008, trazem números que evidenciam a violação dos direitos humanos da população LGBT causada pelo preconceito e pela violência.

De modo qualitativo, a pesquisa de Alencar (2008, p. 6) enfatiza o depoimento de um homossexual para identificar as formas de agressões e ilustrar o sofrimento causado pela homofobia:

(...) Já sofri vários tipos de violência (...). Uma vez, veio dois caras em uma moto (...) um deles me deu um soco, que eu rodei (...). Outra vez, um velho me chamou e me ofereceu cinco reais para transar, eu não aceitei (...), ele me bateu e saiu correndo (...). Uma outra vez, quando távamos no ponto (...), vinham passando os rapazes do tiro de guerra nos xingando e com a mão nos órgãos sexuais, apontando pra gente (...); o nosso ponto é perto de uma igreja evangélica; várias vezes durante o culto, tarde da noite, os pastores nos xingam dizendo: 'queimem no inferno, bando de filhos do demônio' (...)

Não é rara a notícia de crimes homofóbicos com desfechos que relatam a morte de lésbicas, gays, bissexuais, travestis e homossexuais. O relatório de causa mortis, elaborado pelo grupo gay da Bahia, revela o crescente número de assassinatos nas últimas três décadas. Na década de 80 , o número de mortes por motivos homofóbicos era de um caso por semana, e esse número passou para um homicídio a cada três dias na década de 90, sendo o início do terceiro milênio marcado por uma morte a cada dois dias (Mott \& Cerqueira, 2000).
Mott e Cerqueira (2000) e Leony (2006) apontam a dificuldade de obter dados reais sobre a violência contra homossexuais, pois esses crimes nem sempre são monitorados e sistematizados, já que o preconceito enraizado e disseminado pelas instituições 
públicas por vezes se reflete na falta de registros e nas investigações pouco rígidas por parte da polícia em relação a esses crimes. Portanto, estima-se que o número de vítimas da homofobia seja muito maior do que os dados revelados pelos indicadores divulgados pelo Governo e pela mídia.

A primeira iniciativa nesse sentido ocorreu no Rio de Janeiro com a criação do Disque Defesa Homossexual - DDH, sendo citado por Lionço como o primeiro canal de visibilidade para os crimes homofóbicos. A partir dessa iniciativa, o caráter amplo e silencioso da homofobia é constatado no cotidiano dessa população. A homofobia, que antes passava despercebida, atualmente pode ser observada nas "instituições e redes sociais como a família, a escola, o trabalho e a vizinhança" (Lionço, 2008a, p.14).

Lionço descreve que o projeto implantado via Secretaria de Segurança Pública objetiva "à articulação entre o sistema policial e a comunidade". Através desse serviço, os dados que eram noticiados apenas pela mídia, com ênfase nos assassinatos, estão sendo sistematizados, e as outras formas de violência contra homossexuais, em consequência, ganham mais visibilidade.

Recentemente, o jornal Gazeta do Povo publicou a reportagem $\mathrm{Na}$ internet, alunos convocam beijaço na USP contra homofobia em jornal. A matéria citada contextualiza o repúdio dos alunos ao periódico do curso de farmácia $O$ Parasita, que incentivava os alunos a jogarem fezes nos casais homossexuais, e, em troca do favor, receberiam gratuitamente um convite para uma "festa tradicional do curso" (Homofobia..., 2010).

Os alunos que se sentiram ofendidos convocaram a comunidade acadêmica, independentemente da identidade sexual, para um beijo coletivo - beijaço no gramado da universidade a fim de "desparasitar a farmácia Uspiana". Os organizadores do movimento utilizaram ferramentas como blog, Twitter, Orkut e e-mails para divulgar o ato (Homofobia..., 2010).

O recorte abaixo exemplifica o fato de que a propagação da homofobia não ocorre somente em jornais universitários ou na mídia informal, mas que essa prática também está presente nos renomados meios de comunicação.

\begin{abstract}
A homofobia é propagada também por políticos e intelectuais brasileiros: o maior jornal do Nordeste publicou a pena de morte aos homossexuais com o slogan mantenha Salvador limpa, mate uma bicha todo dia; em São Paulo, um político declarou que 'os homossexuais não podem ter os mesmos direitos de pessoas normais'; no Rio de Janeiro, um jornalista escreveu que 'gostaria de ver todos os homossexuais condenados à morte em forno crematório e, mesmo assim, lamentava que sobrassem as cinzas' ${ }^{\prime} .$. Por fim, não podemos nos esquecer do assassinato na Praça da República, em São Paulo, de Edson Néris da Silva, por um grupo de skinheads (autodenominados carecas do $A B C$ ) (Alencar, 2008, p.6)
\end{abstract}

A partir dos exemplos citados acima, concordase com Ribeiro, Soares, Soares, Severo e Moço (2005, p.4) quando afirmam que "os significados atribuídos à sexualidade não estão apenas "na cabeça", mas que constituem e regulam as práticas sociais através de uma variedade de meios, tais como TV, rádio, revistas, internet".

Ao mesmo tempo em que a população, de modo geral, pode acessar na internet artigos acadêmicos que esclarecem as diversidades de identidade de gênero e sexual ou sites de apoio como, por exemplo, a página da ABGLT - Associação Brasileira de Gays, Lésbicas, Bissexuais, Travestis Transexuais, não é incomum encontramos páginas com conteúdos pejorativos e vastas listas de e-mail com conteúdo homofóbico. Essa situação se agrava devido à possibilidade de anonimato em relação ao conteúdo disponibilizado na internet, o que dificulta medidas judiciais. 
Irineu e Bertolini indicam que as intervenções que visam ao combate à violência contra a população LGBT devem dialogar em três esferas: nos movimentos sociais, na sociedade civil e no Estado; desse modo, poderemos manter a perspectiva quanto à "efetivação de direitos sociais em moldes universalizantes e igualitários" (2008, p. 7).

As observações dos autores Irineu e Bertolini, Mott e Cerqueira e Lionço convergem sobre o posicionamento de que a estratégia de envolver o Estado, a população civil e os ativistas do movimento LGBT contra os crimes homofóbicos apresenta resultados positivos na visibilidade das diversas formas de agressão contra homossexuais. A visibilidade decorrente dessas ações ampara a reivindicação dos ativistas para a implementação de leis e programas que combatam a homofobia e acolham as necessidades das vítimas desse tipo de violência.

A partir da imersão do leitor, embora com a necessária brevidade, em algumas nuances da homofobia vivenciada no cotidiano da população LGBT, é nossa intenção, neste momento, apresentar com maior ênfase a conjugação entre o campo da saúde e algumas das especificidades experimentadas por essa população.

\section{Saúde e a população LGBT: demandas e especificidades em questão}

O Ministério da Saúde compreende que todas as formas de discriminação, como o caso da homofobia, "devem ser consideradas como fatores impulsionadores na produção de doenças e sofrimento". Junto ao processo de homofobia, outros fatores de discriminação social devem ser considerados propulsores do processo de adoecimento dessa população, como, por exemplo, o desemprego, o racismo e a inacessibilidade à moradia e à alimentação (Brasil, 2008a, p. 570).

A discussão sobre o processo de adoecimento da população LGBT também requer a especificação dos conceitos de identidade sexual e identidade de gênero. Miller (2002) enfatiza que a abreviatura LGBT pode ser enganadora, já que o primeiro grupo (LGB) se refere à categoria de lésbicas, gays e bissexuais, que devem ser compreendidos como identidades sexuais. E o segundo grupo, representado pela sigla $\mathrm{T}$, é utilizado para se referir aos transgêneros (transexuais e travestis), que devem ser compreendidos como formas de identidade de gênero. Apesar de todos passarem por um processo de adoecimento, o percurso é diferente em cada caso.

\section{Demandas de saúde da mulher lésbica}

O documento Brasil sem Homofobia utiliza o termo lésbicas para designar a homossexualidade feminina, ou seja, "mulheres que mantém relacionamentos afetivos e sexuais com outras mulheres" (Brasil, 2004).

Barbosa e Koyama (2006) problematizam a falta de estudos sobre a saúde da mulher lésbica em território brasileiro, sendo que os estudos a esse respeito estão concentrados nos Estados Unidos. Durante a revisão sistemática desses estudos, as autoras apontam os diferentes problemas de saúde enfrentados pelas mulheres homossexuais.

Nesse sentido, as autoras (2006, p. 1.511) ressaltam que doenças como o câncer de mama e de colo de útero são agravadas devido à baixa utilização dos serviços de saúde por essas mulheres. Entre os fatores associados que conduzem o adoecimento, também são citados "o uso abusivo de drogas 
ilícitas, tabaco, álcool e o grande sofrimento psíquico".

A Rede Feminista de Saúde (2006, p.21) destaca que o sofrimento psíquico "desencadeado pela violência física na família, no trabalho e em lugares públicos" pode ser observado mais frequentemente nas mulheres lésbicas do que nas heterossexuais.

O cotidiano marcado pela "ansiedade, pelo medo e pela expectativa de rejeição decorrente da homofobia" são motivos citados pela Rede Feminista de Saúde (2006, p. 21) como desencadeantes do uso abusivo de drogas, o que se reflete no alto índice de doenças crônicas dessa população.

O dossiê apresentado pela Rede Feminista de Saúde revela os principais motivos que levam à menor procura dos serviços de saúde:

A existência de discriminação, o despreparo dos profissionais para lidar com as especificidades dessa população, as dificuldades de essas mulheres se assumirem como homo ou bissexuais e, por fim, a negação do risco quanto às doenças sexualmente transmissíveis (2006, p. 19)

Quanto às doenças sexualmente transmissíveis, a Rede Feminista de Saúde (2006, p. 18) preocupa-se com duas vertentes. A primeira vertente está relacionada ao desconhecimento dessas mulheres em relação ao risco das doenças sexualmente transmissíveis ao manterem relações sexuais com outras mulheres. A segunda vertente é referente à observação de doenças como $\mathrm{HPV}$, herpes genital e tricomoníase em mulheres que nunca tiveram relações heterossexuais.

De modo geral, Barbosa e Koyama (2006) sugerem que parte do mito de que mulheres que se relacionam com outras mulheres não são susceptíveis a doenças sexualmente transmissíveis é originado da escassez de pesquisas sobre o tema e da não especificidade dos questionários aplicados no levantamento de dados, apresentando a falha de não especificarem os resultados de mulheres que mantêm relacionamentos unicamente homossexuais.

\section{Demandas de saúde do homossexual masculino}

A palavra gay é utilizada para designar a homossexualidade masculina, ou seja, homens que mantêm relações afetivas e sexuais com outros homens (Brasil, 2004).

Valle (2002) expõe que a homossexualidade masculina foi relacionada com a AIDS desde a década de 80, devido à disseminação de ideias negativas sobre essa população, tendo a referida síndrome sido denominada doença gay.

As consequências da associação da homossexualidade masculina com a AIDS foram evidenciadas por Nunan (2004, p.6):

Os homossexuais são profundamente discriminados e têm os seus direitos humanos violados em diversos setores da sociedade, incluindo o ambiente domésticofamiliar, acesso a trabalho e moradia, locais públicos, instituições escolares e diversos órgãos governamentais, tais como a polícia e o exército

De acordo com Nunan (2004, p. 6), a visão negativa que a sociedade apresenta sobre a homossexualidade pode ser internalizada pelo gay, gerando "sentimentos de inferioridade em relação aos heterossexuais e incapacidade de alcançar objetivos que contradigam o preconceito". Nesse sentido, o autor sustenta que o preconceito internalizado pode desencadear questionamentos no homossexual masculino sobre o seu valor como indivíduo e, em casos extremos, gerar o ódio por si mesmo. 
A baixa autoestima gerada pelo preconceito internalizado por essa população é citada por Nunan (2004, p.7) como desencadeadora de:

episódios depressivos, sentimentos de culpa, medo, desconfiança, confusão, insegurança, ansiedade, vergonha, isolamento social, dificuldades de estabelecer e manter relacionamentos amorosos, disfunções sexuais, hostilidade, abuso de álcool e drogas, distúrbios alimentares e comportamento ou ideação suicida

A desvinculação da relação direta da homossexualidade masculina com a AIDS e com transtornos mentais permitiu grandes mudanças referentes às políticas públicas e aos órgãos reguladores de categorias profissionais da área da saúde, além de refletir positivamente sobre o autoconceito dos indivíduos que compõem essa população. Lionço sintetiza o processo de despatologização da homossexualidade da seguinte forma:

A retirada do termo homossexualismo do Manual Diagnóstico de Transtornos Mentais da Associação Psiquiátrica Americana, na década de 80 , que se desdobrou, na década de 90, na retirada do mesmo termo da Classificação Estatística Internacional de Doenças e Problemas Relacionados à Saúde da Organização Mundial da Saúde (CID/ OMS), se sustentou na afirmação de que a homossexualidade não seria patológica (2009, p. 52)

A atenção à saúde do homossexual masculino para além das questões da AIDS vem ganhando visibilidade nos últimos anos, primeiramente com a implementação do Programa Brasil sem Homofobia e, recentemente, com a Política Nacional de Saúde do Homem, que, de acordo com informações do Ministério da Saúde, apresenta como um dos seus objetivos a atenção integral ao gay como estratégia voltada para a promoção da equidade para esse grupo social (Brasil, 2008c).

\section{Os transgêneros e as demandas de saúde}

Apesar das homossexualidades não serem mais vistas como fatores patológicos no âmbito da saúde, podemos observar que a categoria dos transgêneros, composta pelos transexuais e travestis, não foi incluída nesse processo.

Os autores Lionço (2009) e Ventura e Schram (2009) destacam a ampliação dos transtornos e desvios de ordem mental referentes ao transtorno de identidade de gênero encontrados no lançamento da DSM III, DSM IV bem como no CID-10. O diagnóstico de transtorno de identidade de gênero abrange a população de transexuais e travestis.

O debate feito por Aran sobre a patologização da transexualidade faz um apanhado geral sobre os conceitos difundidos na psiquiatria e na Psicologia. Em linhas gerais, a autora crítica o fato de o transexualismo ainda ser considerado uma patologia por ser definido como um "transtorno de identidade devido à não conformidade entre a relação binária sexo e gênero e também poder ser vista como uma psicose, já que o transexual apresenta uma suposta recusa da diferença sexual"(2006, p.49).

A crítica de Aran sobre essas concepções inicia-se pelo diagnóstico, que é "realizado com base nos sistemas de sexo e gênero, convertendo-se num sistema regulador da sexualidade", ou seja, o transexual masculino supostamente deve apresentar o desejo de se relacionar com mulheres, e o transexual feminino deve apresentar interesse por homens.

As autoras Aran, Murta e Lionço (2009) problematizam a necessidade do diagnóstico de transtorno de gênero para os transexuais como condição de acesso ao tratamento da rede pública. 
Geralmente, o transexual procura os serviços de saúde da rede pública por apresentar o desejo de realizar a cirurgia de transgenitalização. Aran, Zaidhaft e Murta realizaram uma pesquisa com essa população no Hospital Universitário Clementino Fraga Filho e observaram que a "demanda pela cirurgia de readequação sexual surge junto à certeza de pertencimento a outro gênero". A importância do tratamento cirúrgico é evidenciada a partir do depoimento de uma transexual:

É porque eu não me penso neste corpo... Embora eu reconheça que biologicamente sou do sexo masculino, para mim, eu não sou homem. Foi isso que me fez procurar ajuda, eu vivia entrando em depressão... Eu só quero levar a minha vida normalmente, sem esses problemas, ser um ser humano normal, ter os direitos que eu não tenho (Aran, Zaidhaft, \& Murta, 2008, p.74)

As análises de todos os relatos coletados por Aran et al. apresentam algo em comum, a condição de intenso sofrimento psíquico, que "aparece sob forma de tentativas de suicídio, depressão, transtornos alimentares e angústia das mais diversas formas", provocado não apenas pelo não pertencimento ao sexo biológico mas também pelas condições de vulnerabilidade social, como a dificuldade de se inserir no mercado formal de trabalho devido a problemas com a documentação. A entrevistada apresentou suas dificuldades de se vincular a um emprego através do seguinte relato:

Eu já pensei em suicídio várias vezes. Eu tenho entrado em muito desespero por causa disso (dificuldade de arranjar emprego). Eu acho que, mesmo operando, ainda vão continuar os problemas por causa da mudança de nome. Eu vou vivendo a minha vida, entro em depressão, saio da depressão... Eu não sei até quando vou conseguir sair da depressão... Eu nunca trabalhei de carteira assinada, só faço bicos... Eles não me consideram apta para exercer a função por causa disso (transexualismo), sendo que já estava tudo pronto para assinar a minha carteira. Eu fui discriminada (Aran et al. 2008, pp. 74-75)
A dificuldade com a documentação explicitada no relato acima também é problematizada por Ventura e Schramm (2009), apontando a inexistência de legislações brasileiras que assegurem o direito do transexual de mudar o primeiro nome e o sexo nos registros oficiais.

De acordo com Aran etal., os constrangimentos provocados pela dificuldade em realizar mudanças na identidade civil são constantes, e o principal prejuízo é notado nas relações de trabalho, "contudo, também foram referidos problemas no local de estudo, na obtenção de plano de saúde, na solicitação de crédito, entre outros" (2008, p. 76).

Quanto à classificação das travestis dentro da gama de doenças de identidade de gênero do CID-10, Lionço esclarece que, lamentavelmente, elas são contempladas na categoria das parafilias, termo encontrado na "linguagem moderna para designar as perversões sexuais, tais como a pedofilia" (2009, p. 54).

Lionço também comenta que os travestis e os transexuais constituem indivíduos pertencentes a um gênero que não correspondem linearmente ao sexo de nascimento, sendo que a diferenciação ocorre devido ao fato de que os travestis sustentam a duplicidade sexual. Ao mesmo tempo em que investem na construção de um "corpo para ser reconhecido pelo outro como um corpo feminino", também não apresentam sentimentos de repúdio quanto a sua característica sexual primária.

Apesar de viverem experiências bastante próximas, Lionço evidencia o grande "divisor de águas no acesso dos serviços de saúde referentes às mudanças corporais permanentes" (2009, p. 55).

O Conselho Federal de Medicina, através da Resolução no 1.652/02, determina que 
apenas as pessoas que apresentarem o diagnóstico de transexualismo terão o direito de modificar suas características sexuais secundárias, como podemos observar nos seguintes artigos:

Art. 1을 Autorizar a cirurga de transgenitalização do tipo neocolpovulvoplastia e/ou procedimentos complementares sobre gônadas e caracteres sexuais secundários como tratamento dos casos de transexualismo. Art. 2o Autorizar, ainda a título experimental, a realização de cirurgia do tipo neofaloplastia e/ou procedimentos complementares sobre gônadas e caracteres sexuais secundários como tratamento dos casos de transexualismo.

Diante da dificuldade ao acesso a um tratamento de readequação corporal seguro, as travestis ficam à mercê do uso indiscriminado de hormônios e das bombadeiras, termo utilizado para a rede ilegal de pessoas que oferecem a essa população o serviço de modificações corporais através da aplicação de silicone industrial. Sampaio exemplifica a técnica utilizada por elas:

As bombadeiras possuem conhecimentos e técnicas sofisticadas no que diz respeito à aplicação do silicone líquido industrial. Prescrevem várias indicações na pré e na pós-aplicação, como remédios a serem tomados, dias de repouso, tudo isso para o silicone 'não descer para os pés'. As sessões de aplicação são realizadas na própria casa da bombadeira ou na casa da cliente, agendada por telefone com antecedência. Elas são longas e dolorosas. Várias seringas são aplicadas em cima da região a ser bombada, marcada antes com lápis de olho. As agulhas são de uso veterinário e geralmente não são antecedidas por nenhum tipo de anestesia. Após a aplicação, os furos são fechados com esmalte de unha ou super bond e cobertos por um recorte de papelão. As aplicações são cobradas por litro de silicone, variando entre trezentos e quatrocentos reais $(2008$, p. 4)
A pesquisa feita por Sampaio mostra evidências de que os travestis residentes nas regiões metropolitanas migram para a capital em busca de melhores técnicas de readequação corporal e pela crença de que nos grandes centros urbanos o mercado do sexo é mais lucrativo.

Souza (2009) e Sampaio (2008) constataram que a prostituição é a fonte de renda mais comum entre os travestis. Sampaio ressalta ainda que a maioria das travestis apresenta baixa escolaridade, o que impossibilita a inserção no mercado formal de trabalho. A discriminação, muitas vezes combinada com o preconceito étnico racial, também constitui uma das barreiras que impossibilitam outra fonte de renda além da prostituição.

Sampaio afirma que, na maioria dos casos, a prostituição "acaba sendo a única alternativa de prover as necessidades materiais" (2008, p.2). Para o travesti, a prostituição também significa estabelecer laços afetivos, pois dentro desse cenário há possibilidades de contato com pessoas que vivem nas mesmas condições, ou seja, as travestis formam uma rede social na qual podem trocar elementos de feminilidade com o objetivo de aprimorar a construção da sua identidade.

\section{Conclusão}

A Lei Orgânica de Saúde no 8.080/90 apresenta, em seu terceiro artigo, o conceito ampliado de saúde, reconhecendo que a saúde "não é apenas a ausência de doenças", mas resultante das "condições de alimentação, habitação, educação, renda, meio ambiente, trabalho, emprego, lazer, liberdade, acesso e posse da terra e acesso aos serviços de saúde" (Brasil, 1990).

A partir desse prisma, múltiplas causas são expostas na determinação do adoecimento da população LGBT. Lionço sinaliza a necessidade de políticas públicas de saúde 
para essa população, "mediante a reflexão e o reconhecimento da condição de vulnerabilidade em relação aos direitos humanos" (2008, p.12).

A identidade sexual e a identidade de gênero são vertentes enfatizadas por Lionço (2008, p.19) que podem constituir conceitos sem definição e, em consequência, o desconhecimento dos profissionais da área da saúde, acarretando déficit de encaminhamentos pertinentes à "especificação da realidade de vida e saúde" da população LGBT. O desconhecimento das redes de apoio e das políticas publicas e até mesmo a generalização da problemática pode configurar, logo, uma barreira para o acesso dessa população a um serviço de saúde que a atenda de forma integral.

Dessa forma, Lionço ressalta que é necessário que os profissionais da área da saúde tenham maior proximidade com as políticas públicas e com as problemáticas específicas da população LGBT para a qualificação dos serviços prestados pelas diversas áreas.

Portanto, os profissionais que atuam na área de saúde, incluindo psicólogos, terapeutas ocupacionais, assistentes sociais e os diversos agentes da saúde, devem estar atentos à reação em cadeia que implica o processo de vulnerabilidade que leva ao adoecimento dessa população, bem como às políticas públicas que facilitam o acesso ao sistema de saúde.

\section{Michelle Rodrigues Cardoso}

Terapeuta Ocupacional pela Universidade Federal do Paraná. Residente do Programa Saúde da Mulher na Residência Integrada Multiprofissional em Atenção Hospitalar do Hospital de Clínicas, Universidade Federal do Paraná, PR - Brasil.

E-mail: mrc.economia@gmail.com

\section{Luís Felipe Ferro}

Mestre e Doutorando em Psicologia Social pela Universidade de São Paulo - USP

Docente do departamento de Terapia Ocupacional da Universidade Federal do Paraná, UFPR - PR - Brasil.

E-mail: luisfelipeferro@gmail.com

Endereço para envio de correspondência:

Av. Mal. Deodoro, 1096, ap. 05, Centro. Curitiba, Paraná - PR. CEP: 80060-010 


\section{Referências}

Alencar, W. A. O. (2008). Cultura de violência: a produção de práticas homofóbicas em Juazeiro do Norte (1990-2007). Trabalho apresentado no XXI ERED/ARAJU. Cariri. Recuperado em 17 abril, 2010 de http://www.urca.br/ered2008/CDAnais/ pdf/SD2_files/Willame_ALENCAR.pdf.

Aran, M. (2006). A transexualidade e a gramática normativa do sistema sexo-gênero. Ágora, 9(1),49-63.

Aran, M., Zaidhaft, S., \& Murta, D. (2008). Transexualidade: corpo, subjetividade e saúde coletiva. Psicologia \& Sociedade, 20(1), 70-79.

Aran, M., Murta, D., \& Lionço, T. (2009). Transexualidade e saúde pública no Brasil. Ciência \& Saúde Coletiva, 14(4), 1141-1149.

Barbosa, M. R., \& Koyama, M. A. H. (2006). Mulheres que fazem sexo com mulheres: algumas estimativas para o Brasil. Cad. Saúde Pública, 22(7), 1511-1514.

Brasil. Presidência da República. (1990).Lei no 8.080, de 19 de serembro de 1990. Dispõe sobre as condições para a promoção, proteção e recuperação da saúde, a organização e o funcionamento dos serviços correspondentes e dá outras providências. Recuperado em 29 maio, 2010 de http://www. planalto.gov.br/ccivil_03/Leis/L8080.htm

Brasil. Ministério da Saúde. (2004). Brasil sem Homofobia: Programa de Combate a Violência e à Discriminação contra GLTB e de Promoção da Cidadania Homossexual. Brasília, DF: Autor.

Brasil. Ministério da Saúde. (2008a). Saúde da população de gays, lésbicas, bissexuais, travestis e transexuais. Rev. Saúde Pública, 42(3), 570-573.

Brasil. Ministério da Saúde. (2008b). Painel de Indicadores do SUS no5 - Prevenção de Violências e Cultura de Paz. Brasília, DF: Autor.

Brasil. Ministério da Saúde. (2008c). Política Nacional de Atenção Integral à Saúde do Homem. Brasília, DF

Conselho Federal de Medicina. (2002). Resolução $n^{\circ}$. 1562/2002. Dispõe sobre a cirurgia de transgenitalismo e revoga a Resolução GM n. 1482/97. Recuperado em 30 maio, 2010 de http://www.gendercare.com/library/cfmtrans.html

$\mathrm{Na}$ internet, alunos convocam "beijaço' na USP contra homofobia em jornal. (2010, 03 de maio). Gazeta do Povo, Curitiba. Recuperado em 8 de novembro, 2010 de http://www.gazetadopovo.com.br/vidaecidadania/ conteudo.phtml $\mathrm{tl}=1 \& \mathrm{id}=998831 \& \mathrm{tit}=\mathrm{Na}$-internet-alunosconvocam-beijaco-na-USP-contra-homofobia-em-jornal.

Irineu, A. B., \& Bertolini, L. V. (2008). A violência contra lésbicas, gays, bissexuais, travestis e transexuais na agenda da segurança pública: entre o passado, o dito e o feito nos Centros de Referência e Combate a Crimes de Homofobia de Mato Grosso. Fazendo Gênero, 8(1), 1-7.

Leony, M. C. (2006). Homofobia, controle social e políticas públicas de atendimento. Pernambuco. Recuperado em 03 abril, 2010, da ADEPOL: http://www.adepol-se.org.br/Download/Artigo_ homofobia_Publica\%C3\%A7\%C3\%A3o2\%5B1\%5D.doc

Lionço, T. (2009). Atenção integral à saúde e a diversidade sexual no processo transexualizador do SUS: avanços, impasses, desafios. PHYSIS: Rev. Saúde Coletiva, 19(1), 43-63.

Lionço, T. (2008a) Que direito à saúde para a população GLBT? Considerando direitos humanos, sexuais, reprodutivos em busca da integralidade e da equidade. Saúde Soc., 17(2), $11-21$.
Lionço, T. (2008b). Bioética e sexualidade: o desafio para a superação de práticas correcionais na atenção à saúde de travestis e transexuais. Série Anis, 54, 1-6.

Miller, J. (2002). Creating inclusive helthcare environment for the GLBT community. The Official Newsletter of the Networker for Lesbian, Gay and Bissexual Concerns in Occupational Therapy, 9(1), 1-10.

Mott, L., \& Cerqueira, M. (2000). Causa mortis: homofobia. Violação de direitos humanos e assassinato de homossexuais no Brasil. Salvador, BA: Editora Grupo Gay da Bahia.

Nascimento, M. A. N. (2010). Homofobia e homofobia interiorizada: produções subjetivas de controle heteronormativo? Athenea Digital, 1(17), 227-239.

Nunan, A. (2004). Violência doméstica entre casais homossexuais: o segundo armário? PSICO, 35(1), 69-78.

Okita, H. (2007). Homossexualidade: da opressão à libertação (2a. ed.). São Paulo: Sundermann

Paiva, V. (2006). Analisando cenas e sexualidades: a promoção da saúde na perspectiva dos direitos humanos. In V. Paiva. Sexualidad, estigma y derechos humanos. Desafíos para el acesso a la salud en América Latina. Lima, Peru: FASPA/ UPUCH.

Ramos, S., \& Carrara, S. (2006). A constituição da problemática da violência contra homossexuais: a articulação entre o ativismo e a academia na elaboração de políticas públicas. PHYSIS: Rev. Saúde Coletiva, 16(2), 185-2005.

Rede Feminista de Saúde. (2006). Dossiê Saúde das Mulheres Lésbicas: promoção da equidade e da integralidade. Belo Horizonte: Autor.

Ribeiro, C. R. P., Soares, G. F., Soares, B. E. S., Severo, D. M. B., \& Moço, L.R. (2005). Representações culturais de sexualidade: construção, essência, heteronormatividade, ato sexual, sentimentos. Enseñanza de las Ciências, 7, 1-4

Sampaio, J. O. (2008). Redes sociais engendradas: notas sobre o caráter associativo entre os travestis em São Luis, Maranhão. Fazendo Gênero - Corpo, Violência e Poder, 8, 1-7.

Sousa , P J., Abrão, F. M. S. Costa, A. M. C \& \& Ferreira, L. O. C. F. (2009) Humanização no acolhimento de gays, lésbicas, bissexuais, travestis e transexuais na atenção básica: reflexões bioéticas para enfermagem. In Anais do Segundo Seminário Nacional de diretrizes para enfermagem na atenção básica em saúde, $2^{\circ}$ SENABES. Recife, PE: Associação Brasileira de Enfermagem. Recuperado em 15 março, 2010, da ABEN: http://www.abeneventos.com.br/SENABS/cd anais/pdf/ id141r0.pdf

Souza, A. C. B. (2009). Resenha do livro Travesti - prostituição, sexo, gênero e cultura no Brasil. Ciência e Saúde Coletiva, 14(4), 1309-1310.

Valle, C. G. (2002). Identidades, doença e organização social: um estudo das "pessoas vivendo com HIV e AIDS". Horizontes Antropológicos, 8(17), 179- 210.

Ventura, M., \& Schramm, F. R. (2009). Limites e possibilidades: do exercício da autonomia nas práticas terapêuticas de modificação corporal e alteração da identidade sexual. PHYSIS: Rev. Saúde Coletiva, 19(1), 65-93. 